Long-Term Deutetrabenazine Treatment Is Associated With Continued Improvement in Tardive Dyskinesia in the Completed 3-Year Open-Label Extension Study

Robert A. Hauser, MD, MBA ${ }^{1}$, Hadas Barkay, $\mathrm{PhD}^{2}$, Hubert H. Fernandez, $M D^{3}$, Stewart A. Factor, $D^{4}$, Joohi Jimenez-Shahed, $\mathrm{MD}^{5}$, Nicholas Gross, $\mathrm{MS}^{6}$, Leslie Marinelli, $\mathrm{BS}^{6}$, Amanda Wilhelm, $\mathrm{PhD}^{6}$, Mark Forrest Gordon, MD ${ }^{6}$, Juha-Matti Savola, MD, $\mathrm{PhD}^{7}$ and Karen E. Anderson, $\mathrm{MD}^{8}$

${ }^{1}$ University of South Florida, Parkinson's Disease and Movement Disorders Center, Tampa, FL, USA, ${ }^{2}$ Teva Pharmaceutical Industries Ltd., Netanya, Israel, ${ }^{3}$ Cleveland Clinic, Cleveland, OH, USA, ${ }^{4}$ Emory University, Atlanta, GA, USA, ${ }^{5}$ Icahn School of Medicine at Mount Sinai, New York, NY, USA, ${ }^{6}$ Teva Pharmaceutical Industries Ltd., West Chester, PA, USA, ${ }^{7}$ Teva Pharmaceutical Industries Ltd., Basel, Switzerland, and ${ }^{8}$ Georgetown University, Washington, DC, USA

Presenting Author: Robert A. Hauser

\section{Evaluation of the Safety of Deutetrabenazine at Higher Doses to Treat Chorea in Huntington's Disease}

Samuel Frank, $\mathrm{MD}^{1}$, Christina Vaughan, MD, MHS ${ }^{2}$, David Stamler, $\mathrm{MD}^{3}$, David Oakes, $\mathrm{PhD}^{4}$, Mat D. Davis, $\mathrm{PhD}^{5}$, Nicholas Gross, $\mathrm{MS}^{5}$, Mark Forrest Gordon, $\mathrm{MD}^{5}$, Juha-Matti Savola, MD, $\mathrm{PhD}^{6}$, Maria Wieman, $\mathrm{MPH}^{5}$, Shirley Eberly, $\mathrm{MS}^{4}$, Elise Kayson, $\mathrm{MS}^{4}$, Jacquelyn Whaley, $\mathrm{MS}^{7}$, Jody Goldstein, $\mathrm{BS}^{8}$, Claudia M. Testa, MD, $\mathrm{PhD}^{9}$ and on behalf of the Huntington Study Group ARC-HD Investigators

\footnotetext{
${ }^{1}$ Beth Israel Deaconess Medical Center/Harvard Medical School, Boston, MA, USA, ${ }^{2}$ University of Colorado, Aurora, CO, USA, ${ }^{3}$ Teva Pharmaceutical Industries Ltd., La Jolla, CA, USA, ${ }^{4}$ University of Rochester, Rochester, NY, USA, ${ }^{5}$ Teva Pharmaceutical Industries Ltd., West Chester, PA, USA, ${ }^{6}$ Teva Pharmaceutical Industries Ltd., Basel, Switzerland, ${ }^{7}$ Center for Health + Technology, University of Rochester, Rochester, NY, USA, ${ }^{8}$ Huntington Study Group, Rochester, NY, USA, and ${ }^{9}$ Virginia Commonwealth University, Richmond, VA, USA
}

Presenting Author: Samuel Frank

\begin{abstract}
Background. In the First-HD pivotal trial, the maximum deutetrabenazine dose evaluated to treat chorea associated with Huntington's disease (HD chorea) was $48 \mathrm{mg} / \mathrm{d}$, which is the approved maximum dose for this population. In ARC-HD, an open-label extension study evaluating the long-term efficacy and safety of deutetrabenazine to treat HD chorea, dosage ranged from $6 \mathrm{mg} / \mathrm{d}$ to $72 \mathrm{mg} / \mathrm{d}$, with doses $\geq 12 \mathrm{mg} / \mathrm{d}$ administered twice daily. Doses in ARC-HD were increased by $6 \mathrm{mg} / \mathrm{d}$ per week in a responsedriven manner based on efficacy and tolerability until $48 \mathrm{mg} / \mathrm{d}$ (Week 8). At the investigator's discretion, further increases were permitted by $12 \mathrm{mg} / \mathrm{d}$ per week to a maximum of $72 \mathrm{mg} / \mathrm{d}$. This post-hoc analysis evaluates the safety and tolerability of deutetrabenazine $>48 \mathrm{mg} / \mathrm{d}$ compared to $\leq 48 \mathrm{mg} / \mathrm{d}$ to treat HD chorea in ARC-HD.
\end{abstract}

Methods. Patient counts and safety assessments were attributed to patients when they received a dose of either $\leq 48 \mathrm{mg} / \mathrm{d}$ or $>48$ $\mathrm{mg} / \mathrm{d}$. For 9 selected adverse events (AEs), we compared AE rates adjusted for duration of drug exposure (as number of AEs/year) at $\leq 48 \mathrm{mg} / \mathrm{d}$ or $>48 \mathrm{mg} / \mathrm{d}$. The AE rates were determined after titration when participants were on stable doses of deutetrabenazine.

Results. All 113 patients were exposed to doses $\leq 48 \mathrm{mg} / \mathrm{d}$ (177.1 patient-years) and 49 patients were ever exposed to doses $>48$ $\mathrm{mg} / \mathrm{d}$ (74.1 patient-years). In patients taking deutetrabenazine $>48 \mathrm{mg} / \mathrm{d}$ compared to $\leq 48 \mathrm{mg} / \mathrm{d}$ after the titration period, there were no apparent differences in exposure-adjusted AE rates. Conclusions. Based on clinical experience, some patients with HD may benefit from doses higher than $48 \mathrm{mg} / \mathrm{d}$ to adequately control chorea. These doses were tolerated without apparent increase in the exposure-adjusted rates of selected AEs after titration. This analysis does not address the occurrence of other 